\title{
Influence of the Fast-acting Inhibitor of Plasminogen Activator on In Vivo Thrombolysis Induced by Tissue-Type Plasminogen Activator in Rabbits Interference of Tissue-derived Components
}

\author{
M. Colucci, J. A. Paramo, J. M. Stassen, and D. Collen \\ Center for Thrombosis and Vascular Research, University of Leuven, Belgium
}

\begin{abstract}
The influence of endotoxin-induced elevated plasma levels of the fast-acting inhibitor of plasminogen activator (PA-inhibitor) on thrombolysis was investigated in rabbits with a jugular vein thrombus. Infusion of human tissue-type plasminogen activator (t-PA) produced similar degrees of thrombolysis in control and endotoxin-treated rabbits, although no free t-PA could be demonstrated in plasma of endotoxin-treated animals. Infusion of t-PA in an extracorporeal arteriovenous shunt resulted in loss of thrombolytic activity in endotoxin-treated animals but not in control animals.

Blood clots superfused in vitro with mixtures of t-PA and normal plasma lysed in contrast to clots superfused with t-PA and PA-inhibitor-rich plasma. However, addition of rabbit lung slices to the plasma surrounding the blood clot, reversed the inhibition of thrombolysis by PA-inhibitor-rich plasma. This indicates that tissue-derived factor(s) are involved in the regulation of in vivo thrombolysis. These hypothetical factor(s) are, however, very unstable in plasma, which has thus far precluded their further characterization.
\end{abstract}

\section{Introduction}

Fibrin plays an important role in the regulation of fibrinolysis (1). It markedly stimulates the activation of plasminogen by tissue-type plasminogen activator (t-PA) ${ }^{1}$ and protects plasmin molecules, generated at the clot surface, from rapid inhibition by $\alpha_{2}$-antiplasmin. It thereby mediates effective and clot-specific activation of the fibrinolytic system.

Human plasma and conditioned medium from endothelial cell cultures contain a fast-acting inhibitor of plasminogen activator (PA-inhibitor) that neutralizes both t-PA and urokinase (UK) (2-9). PA-inhibitor has an apparent molecular mass of 40-50 kD and forms an inactive 1:1 molar complex with t-PA

Dr. Colucci's present address is Istituto di Patologia Generale, Universita degli Studi, Bari, Italy. Dr. Paramo's present address is Clinica Universitaria de Navarra, Pamplona, Spain. Address reprint requests to Dr. Collen, Center for Thrombosis and Vascular Research, Campus Gasthuisberg, Herestraat 49, B-3000 Leuven, Belgium.

Received for publication 14 May 1985 and in revised form 17 March 1986.

1. Abbreviations used in this paper: LPS, lipopolysaccharide; PA-inhibitor, fast-acting inhibitor of tissue-type plasminogen activator and urokinase; t-PA, tissue-type plasminogen activator; UK, urokinase.

J. Clin. Invest.

(c) The American Society for Clinical Investigation, Inc.

0021-9738/86/07/0138/07 \$1.00

Volume 78, July 1986, 138-144 (and UK) $(8,9)$. The reaction between t-PA and PA-inhibitor is very rapid, with a rate constant of $10^{7} \mathrm{M}^{-1} \mathrm{~s}^{-1}(2,3)$. Rapid inhibition of t-PA by PA-inhibitor has also been demonstrated in vivo (10). The plasma concentration of PA-inhibitor in healthy subjects is in the nanograms per milliliter range (2-6) but is markedly increased in some pathological conditions $(3,4)$, and in conditions associated with low fibrinolytic activity and a thrombotic tendency (11-13).

Little is known about the effect of fibrin on the interaction between t-PA and PA-inhibitor. Kruithof et al. (2) observed that coagulation of PA-inhibitor-rich plasma prevented the inhibition of t-PA. Zamarron et al. (14), however, concluded that PA-inhibitor can diffuse into the clot and neutralize fibrin-bound t-PA.

Injection of low doses of endotoxin $(1 \mu \mathrm{g} / \mathrm{kg}$ body $\mathrm{wt})$ in rabbits, induces a very marked increase of PA-inhibitor activity in blood without associated changes in platelet count, fibrinogen level, and activated partial thromboplastin time (10). We have now used this model to investigate the effect of high blood levels of PA-inhibitor on the thrombolytic activity of t-PA in vitro and in vivo.

\section{Methods}

\section{Materials}

Human t-PA (two-chain form), human plasminogen, and human fibrinogen were purified by published methods (15-17). Recombinant human t-PA, obtained by expression of the t-PA gene in a mammalian cell system, was supplied by Genentech Inc, South San Francisco, CA (courtesy of Dr. C. F. Hoyng). Fibrinogen was digested with $\mathrm{CNBr}$ as previously described (18). Fibrinogen was labeled with ${ }^{125} \mathrm{I}$ using the Iodo-Gen procedure (19). Escherichia coli 0111:B4 lipopolysaccharide (LPS) W was purchased from Difco Laboratories, Inc., Detroit, MI. The synthetic substrate D-Val-Leu-Lys-pNA (S-2251) was purchased from KabiVitrum, Amsterdam, The Netherlands. D-Ile-Pro-Arg- $\mathrm{CH}_{2} \mathrm{Cl}$, a synthetic inhibitor of t-PA, is characterized elsewhere (20).

The t-PA preparations used in this study had a specific activity of $500,000 \mathrm{IU} / \mathrm{mg}$ as calibrated against the International Reference Preparation for t-PA $(83 / 517)(21)$. This specific activity is five times higher than that reported in our previous studies in which t-PA was calibrated against the International Reference Preparation of Urokinase (66/46).

\section{In vivo experiments}

New Zealand rabbits, weighing 1.9-2.5 kg, were anesthetized by intramuscular injection of $0.4 \mathrm{ml} / \mathrm{kg}$ body wt of Hypnorm (Duphar, Amsterdam, The Netherlands) containing $10 \mathrm{mg} / \mathrm{ml}$ fluanisone and 0.2 $\mathrm{mg} / \mathrm{ml}$ fentanil. Additional Hypnorm $(0.3 \mathrm{ml}$ every $2 \mathrm{~h})$ was administered to maintain anesthesia. Venous blood samples $(1 \mathrm{ml})$ were collected on $4 \%$ trisodium citrate ( 9 vol of blood plus 1 vol of anticoagulant), on citrate plus D-Ile-Pro-Arg- $\mathrm{CH}_{2} \mathrm{Cl}\left(2 \times 10^{-4} \mathrm{M}\right.$ final concentration) or on heparin $(10 \mathrm{U} / \mathrm{ml})$. The blood samples were immediately chilled in melting ice. Plasma was isolated within $10 \mathrm{~min}$ of sampling by brief centrifugation ( $2 \mathrm{~min}$ at $12,000 \mathrm{~g}$ ) and kept on ice until tested, or was frozen 
immediately at $-20^{\circ} \mathrm{C}$. Injections of $E$. coli LPS ( $1 \mu \mathrm{g} / \mathrm{kg}$ body wt) or sterile saline $(1 \mathrm{ml})$ were given intravenously to conscious rabbits $2 \mathrm{~h}$ before the introduction of the jugular vein thrombus. Infusions of t-PA were started about $3 \mathrm{~h}$ after endotoxin injection.

Lysis of jugular vein clots with intravenous $t-P A$. The procedure for the introduction of the radiolabeled ( ${ }^{125} \mathrm{I}$-fibrinogen) thrombus in the jugular vein of the rabbit, and for the quantitation of thrombolysis and isotope recovery is described in detail elsewhere (22). All thrombolysis experiments reported here were carried out in animals with fresh clots aged for $30 \mathrm{~min}$. t-PA was diluted to $24 \mathrm{ml}$ with $0.15 \mathrm{M} \mathrm{NaCl}, 0.01 \%$ Tween 80 and infused intravenously over $4 \mathrm{~h}$ by using a constant rate infusion pump. The infusions were given systemically via the contralateral marginal ear vein or locally through a catheter introduced via the ipsilateral marginal ear vein and advanced into the immediate vicinity of the clot. Thrombolysis, i.e., residual ${ }^{125}$ I-activity in the clots, was measured within 10 min after the infusion had been terminated. Activator-induced thrombolysis was calculated as the difference between the means of the percentage thrombolysis in a given t-PA-infused group (A) and its control group infused with solvent (C), divided by $100-\mathrm{C}(22)$.

Thrombolysis induced by $t-P A$ incorporated into the clot. Unanticoagulated blood $(2 \mathrm{ml})$ from a donor rabbit was mixed with ${ }^{125}$ I-fibrinogen and t-PA ( $25 \mathrm{IU} / \mathrm{ml}$ final concentration) and immediately injected in an isolated jugular vein segment of recipient rabbits. The clot was allowed to age for $30 \mathrm{~min}$, the vein clamps were removed and the blood flow restored, and thrombolysis was assessed after an additional 5 or $90 \mathrm{~min}$.

Binding of infused t-PA to the jugular vein thrombus. This was measured in control and endotoxin-treated rabbits in the following way: $A$ dose of $40,000 \mathrm{IU}$ of $\mathrm{t}-\mathrm{PA} / \mathrm{kg}$ body wt was infused over $1 \mathrm{~h}$, the vein segment was then opened and the clot recovered. The clot was washed for $5 \mathrm{~min}$ in $0.15 \mathrm{M} \mathrm{NaCl}$ and added to a plastic tube containing $2 \mathrm{ml}$ of citrated normal rabbit plasma. After isotope counting the samples were incubated at $37^{\circ} \mathrm{C}$. At intervals, $0.2-\mathrm{ml}$ plasma samples were removed for radioisotope counting and the extent of thrombolysis was calculated from the amount of radioactivity released from the clot.

Infusion of $t-P A$ into extracorporeal arteriovenous shunts. Rabbits with an established jugular vein thrombus were heparinized $(600 \mathrm{U} / \mathrm{kg}$ i.v.); a portex red catheter (Portex Ltd., Hythe, Kent, England) was introduced in the ipsilateral femoral artery and a portex blue catheter was introduced via an ipsilateral marginal ear vein and advanced into the immediate vicinity of the clot. The two catheters were connected via a $100-\mathrm{cm}$ long silicon tubing (internal diam $4 \mathrm{~mm}$ ) filled with sterile saline containing $50 \mathrm{U} / \mathrm{ml}$ heparin. Three-way valves were inserted on both ends of the tubing. The volume of the arteriovenous shunt was $17 \mathrm{ml}$ and a constant flow rate of $5 \mathrm{ml} / \mathrm{min}$ was maintained by using a peristaltic pump. Heparin ( $5 \mathrm{U} / \mathrm{kg}$ per $\mathrm{min}$ ) was infused via the three-way valve at the beginning of the arteriovenous shunt. t-PA $(25,000 \mathrm{IU} / \mathrm{kg}$ body wt) or solvent were infused over $4 \mathrm{~h}$ via this three-way valve and blood samples were collected via the three-way valve at the end of the arteriovenous shunt. Thus, t-PA was in contact with rabbit blood in the extracorporeal circulation for 3 min before reentering into the jugular vein. Thrombolysis was assessed at the end of the infusion as described elsewhere (22).

Lysis of blood clots in the extracorporeal shunt by $t$-PA. Extracorporeal arteriovenous shunts containing a radiolabeled whole blood clot were produced in the following way. A portex red catheter introduced into a femoral artery was connected to a closed reservoir (the filter compartment of a blood transfusion set) containing the labeled clot. The reservoir was then connected via a portex red catheter with the contralateral femoral vein. The volume of the circuit was $15 \mathrm{ml}$ and a constant flow rate of $12 \mathrm{ml} / \mathrm{min}$ was maintained with a peristaltic pump. The labeled blood clot was produced as follows. Aliquots of $2 \mathrm{ml}$ whole rabbit blood containing ${ }^{125}$ I-fibrinogen $(\simeq 200,000 \mathrm{cpm}$ ) were mixed with $4 \mathrm{IU}$ of thrombin (Topostasin, Roche, Brussels, Belgium) and quickly aspirated in a silicon tubing $\left(4 \mathrm{~mm}\right.$ i.d.). The blood was allowed to clot for $1 \mathrm{~h}$ at $37^{\circ} \mathrm{C}$, then segments of $1.5 \mathrm{~cm}$ length were cut off, yielding labeled blood clots of $\sim 0.2 \mathrm{ml}$. The clots were poured into petri dishes and washed at room temperature for $1 \mathrm{~h}$ in $0.15 \mathrm{M} \mathrm{NaCl}$ with several changes. This procedure resulted in complete cross-linking of the fibrin in the clots (23). After isotope counting, the clots were introduced into the reservoir of the arteriovenous shunt. Heparin ( $5 \mathrm{U} / \mathrm{kg}$ per $\mathrm{min}$ ) and t-PA $(12,500 \mathrm{IU} / \mathrm{kg}$ body wt) or solvent were infused over $2 \mathrm{~h}$ into the circuit before the reservoir, and blood samples were collected via a three-way valve distal to the reservoir. The contact time between t-PA and rabbit blood, before the activator reached the clot was $\sim 10 \mathrm{~s}$. The extent of thrombolysis was calculated at the end of the infusion by measuring the residual radioactivity in the clot.

\section{In vitro studies}

Inhibition of fibrin-associated $t-P A$ by $P A$-inhibitor. This was measured in an in vitro system consisting of a radiolabeled blood clot immersed in citrated rabbit plasma. The labeled blood clots were prepared as outlined above with the following modifications. t-PA ( $40 \mathrm{IU} / \mathrm{ml}$ final concentration) was added to the ${ }^{125}$ I-fibrinogen-blood mixture before addition of thrombin. Clots were aged for $30 \mathrm{~min}$ at $37^{\circ} \mathrm{C}$ and then washed in $0.15 \mathrm{M} \mathrm{NaCl}$ for $15 \mathrm{~min}$. After isotope counting, the clots were immersed at $37^{\circ} \mathrm{C}$ in $2 \mathrm{ml}$ control or PA-inhibitor-rich plasma. At intervals (up to $6 \mathrm{~h}$ ) 0.2 -ml plasma samples were removed and the extent of thrombolysis was calculated from the amount of radioactivity released from the clot.

Lysis of blood clots superfused with mixtures of $t-P A$ and plasma or whole blood. The effect of PA-inhibitor on t-PA-induced thrombolysis of a radiolabeled blood clot was measured in the following way. A flatbottomed plastic tube $(1.6 \times 5 \mathrm{~cm})$, containing $1 \mathrm{ml}$ of plasma or blood and a labeled clot, was placed in a waterbath at $37^{\circ} \mathrm{C}$. Plasma and t-PA were continuously transferred from a reservoir and a syringe, both kept at room temperature, into the tube containing the clot. Plasma was perfused by means of a peristaltic pump at a constant rate of $1.2 \mathrm{ml} / \mathrm{min}$ and t-PA by means of a constant rate infusion pump at a rate of 210 $\mathrm{IU} / \mathrm{min}$. Plasma and t-PA were mixed before delivery in the tube. The clots were superfused with plasma containing $175 \mathrm{IU}$ of t-PA $/ \mathrm{ml}$, which had been mixed for either 5 or $70 \mathrm{~s}$ before contact with the clot. In the experiments with whole blood, the infusion rate of t-PA was adjusted, according to the hematocrit, in order to maintain a plasma concentration of $175 \mathrm{IU} / \mathrm{ml}$.

The volume in the tube was maintained constant by aspiration of liquid via a tubing with the end fixed at the meniscus in the test tube. Aliquots of plasma for assay of t-PA and PA-inhibitor were collected via the aspirating tube, 25 and $50 \mathrm{~min}$ after the start of the infusion. The extent of thrombolysis was calculated, $60 \mathrm{~min}$ after the start of the infusion, from the residual radioactivity in the clot. In these experiments radiolabeled clots with a volume of $25 \mu \mathrm{l}(2.5 \times 5 \mathrm{~mm})$ were prepared as outlined above. PA-inhibitor-rich blood and plasma were obtained from endotoxin-treated rabbits $4 \mathrm{~h}$ after injection of $1 \mu \mathrm{g} / \mathrm{kg}$ body wt of E. coli LPS. Plasma samples were always pools of at least three donor animals, whereas whole blood of individual rabbits was used. Either fresh plasma or plasma stored at $-20^{\circ} \mathrm{C}$ was used. PA-inhibitor levels were $16 \pm 6 \mathrm{U} / \mathrm{ml}$ in control and $265 \pm 65 \mathrm{U} / \mathrm{ml}$ in inhibitor-rich plasma pools, measured as described below. Fibrinogen, plasminogen, and $\alpha_{2-}$ antiplasmin levels were similar in control and PA-inhibitor-rich plasma and did not change significantly during the course of the experiments.

Effect of lung tissue slices on the lysis of superfused blood clots. Slices of lung tissue were prepared as follows. Rabbits were anesthetized by intravenous injection of sodium pentobarbital $(25 \mathrm{mg} / \mathrm{kg})$. After the chest was opened, a portex yellow catheter was introduced into the pulmonary artery and the lungs were perfused with $100 \mathrm{ml}$ of $0.15 \mathrm{M} \mathrm{NaCl}$ containing $0.1 \%$ glucose. The lungs were then removed, separated from the heart and other attached tissues, and transferred to petri dishes containing serum-free Eagle's minimal essential medium (Gibco Ltd., Paisley, Scotland). Slices of $10 \times 5 \mathrm{~mm}$ were cut out from the peripheral region of the lungs with a razor blade. Several longitudinal and transversal incisions were made on the lung slices in order to increase the external surface. The slices were then rinsed in fresh medium and added to the tube containing the radiolabeled clot. Lysis following superfusion with mixtures of t-PA and plasma was then measured as described above. 


\section{Other assays and procedures}

t-PA activity in plasma was measured by the fibrin plate method (24) as reported (15). The lower detection limit of this assay is 1 IU of t-PA/ ml. t-PA-related antigen was measured using a two-site immunoradiometric assay (25). PA-inhibitor activity was assayed by an amidolytic method as described elsewhere (10), and expressed in units of t-PA inhibited by $1 \mathrm{ml}$ of the assay solution. In this assay both plasma and t-PA controls were acidified with $0.16 \mathrm{M} \mathrm{HCl}$. Fibrinogen, $\alpha_{2}$-antiplasmin and plasminogen were assayed as previously described $(22,26,27)$. Activated partial thromboplastin time and platelet count were performed by standard laboratory assays. Gel filtration of plasma samples $(0.5 \mathrm{ml})$ was performed on an Ultrogel AcA 44 column $(30 \times 1.6 \mathrm{~cm})$ equilibrated with $0.02 \mathrm{M}$ Tris $\mathrm{HCl}, 0.3 \mathrm{M} \mathrm{NaCl}$ buffer, $\mathrm{pH} 7.4$, containing $0.01 \mathrm{M}$ trisodium citrate, and $0.02 \%$ Tween 80 . The flow rate was $10 \mathrm{ml} / \mathrm{h}$ and fractions of $1 \mathrm{ml}$ were collected.

\section{Results}

All reported results were obtained with recombinant t-PA but control experiments performed with t-PA isolated from melanoma cell culture gave very similar or identical results.

\section{In vivo experiments}

Lysis of jugular vein clots with intravenous $t-P A$. The extent of thrombolysis induced by t-PA in control and endotoxin-treated rabbits is shown in Fig. 1. Systemic infusion of t-PA resulted in a dose-dependent degree of lysis that was similar in both animal groups. Locally infused activator caused a much higher degree of thrombolysis, which was also similar in control and endotoxintreated rabbits. Infusion of solvent resulted in a low degree of spontaneous lysis. The isotope recovery (not shown) was $>95 \%$, indicating that no significant losses of labeled material by embolization had occurred.

The antigen levels of t-PA in the blood of rabbits during infusion of the thrombolytic agent were proportional to the infusion rate of t-PA (not shown). The t-PA levels (antigen and activity) in rabbit plasma during systemic infusion of 150,000 IU of t-PA/kg body wt are shown in Fig. 2. In control animals the t-PA activity recovered in the plasma euglobulin fraction correlated well with the antigen levels (Fig. $2 \mathrm{~A}$ ), whereas virtually no activity $(<1 \mathrm{IU} / \mathrm{ml})$ was detected in the plasma of endotoxintreated animals (Fig. $2 B$ ).

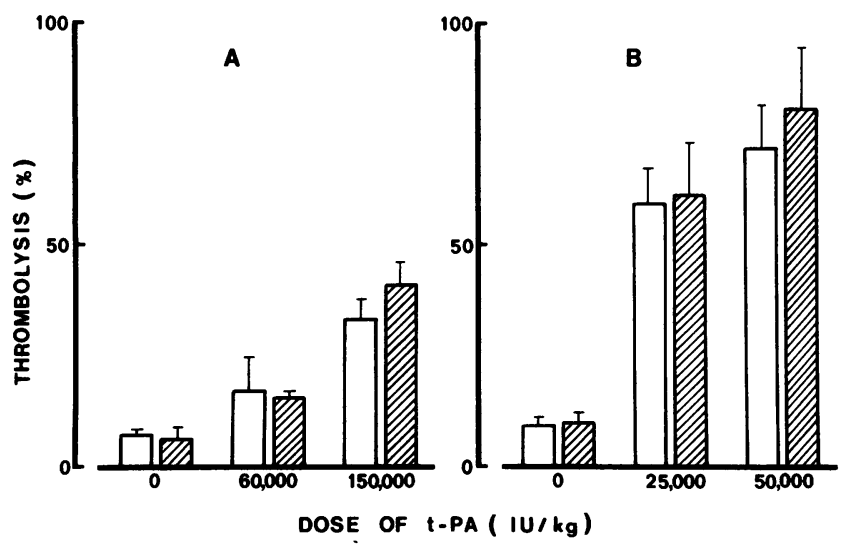

Figure 1. Lysis of jugular vein clots with intravenous t-PA. Thrombolysis after systemic (A) or local (B) infusion of t-PA in control (open bars) and endotoxin-treated (hatched bars) rabbits. Results are the mean of three experiments. The vertical lines represent SD.
Gel filtration of plasma samples obtained from blood collected on D-Ile-Pro-Arg- $\mathrm{CH}_{2} \mathrm{Cl}$ (Fig. 3) revealed that in plasma of control animals most of the t-PA antigen eluted in the albumin region, whereas in plasma of endotoxin-treated animals it eluted with an apparent molecular weight of 100,000 . Because D-IlePro-Arg- $\mathrm{CH}_{2} \mathrm{Cl}$ completely prevents t-PA inhibition by PA-inhibitor in vitro (10), this finding indicates that inhibition of t-PA in endotoxin-treated animals had occurred in vivo and not in the test tube after blood sampling.

The plasma levels of fibrinogen, plasminogen, and $\alpha_{2}$-antiplasmin were not significantly different in the two groups of animals and did not change during t-PA infusion (not shown).

Thrombolysis induced by $t-P A$ incorporated into the clot. The effect of PA-inhibitor on the lysis of jugular vein thrombi made from blood with added t-PA is illustrated in Fig. 4. The extent of thrombolysis of t-PA-containing thrombi within $5 \mathrm{~min}$ after removal of the vein clamps (i.e., during the 30-min interval of clot aging) was much lower than after an additional $90 \mathrm{~min}$, but was similar in control and endotoxin-treated animals. The plasma PA-inhibitor activity in endotoxin-treated rabbits was $225 \pm 70 \mathrm{U} / \mathrm{ml}$.

Binding of infused t-PA to the jugular vein thrombus. t-PA $(40,000 \mathrm{IU}$ per $\mathrm{kg}$ body wt) was infused over $1 \mathrm{~h}$ in rabbits with jugular vein thrombus, and the clot was recovered at the end of the infusion and incubated in normal rabbit plasma. No significant lysis ( $<10 \%$ in $20 \mathrm{~h}, n=2$ ) was observed with clots obtained from either control or endotoxin-treated animals, indicating that, if any t-PA is adsorbed onto the clot, its concentration remains below the inhibiting capacity of control plasma.

Infusion of t-PA into extracorporeal arteriovenous shunts. The following experiments were carried out to assess whether the t-PA-PA-inhibitor complex has thrombolytic activity. t-PA $(25,000 \mathrm{IU} / \mathrm{kg}$ body $\mathrm{wt})$ was infused over $4 \mathrm{~h}$ in the proximal part of the femoro-jugular arteriovenous shunt. t-PA-induced thrombolysis was $35 \%$ in control animals and undetectable in endotoxin-treated rabbits (Fig. 5). The relatively high degree of spontaneous thrombolysis observed in animals infused with solvent is, most probably, due to the high flow rate of blood reinfused into the jugular vein. Assays of t-PA and gel filtration analysis of blood samples collected from the distal part of the arteriovenous shunt revealed complete inhibition of t-PA activity and formation of t-PA-PA-inhibitor complex in endotoxintreated rabbits. In control animals peak t-PA activity in the extracorporeal loop ranged between 25 and $50 \mathrm{IU} / \mathrm{ml}$ of plasma. This activity, however, declined to $<10 \mathrm{IU} / \mathrm{ml}$ in the last hour of infusion due to a spontaneous increase of the PA-inhibitor level.

Lysis of blood clots in the extracorporeal shunt by $t-P A$. A radiolabeled clot was placed into an extracorporeal shunt connecting a femoral artery with the contralateral femoral vein. $\mathrm{t}-\mathrm{PA}(12,500 \mathrm{IU} / \mathrm{kg}$ body $\mathrm{wt})$ was infused over $2 \mathrm{~h}$ into the proximal part of the shunt and was mixed with blood about $10 \mathrm{~s}$ before contact with the clot. The degree of thrombolysis observed at the end of the infusion is illustrated in Fig. 6. In control animals the t-PA-induced lysis was on average $32 \%$ while in animals with high circulating levels of inhibitor it was only $13 \%$. This degree of thrombolysis in endotoxin-treated rabbits is significantly higher $(P<0.05)$ than the degree of thrombolysis in control and endotoxin-treated rabbits infused with solvent. t-PA activity in blood samples taken from the distal part of the extracorporeal circuit was $32 \pm 8 \mathrm{IU} / \mathrm{ml}$ in control animals and 


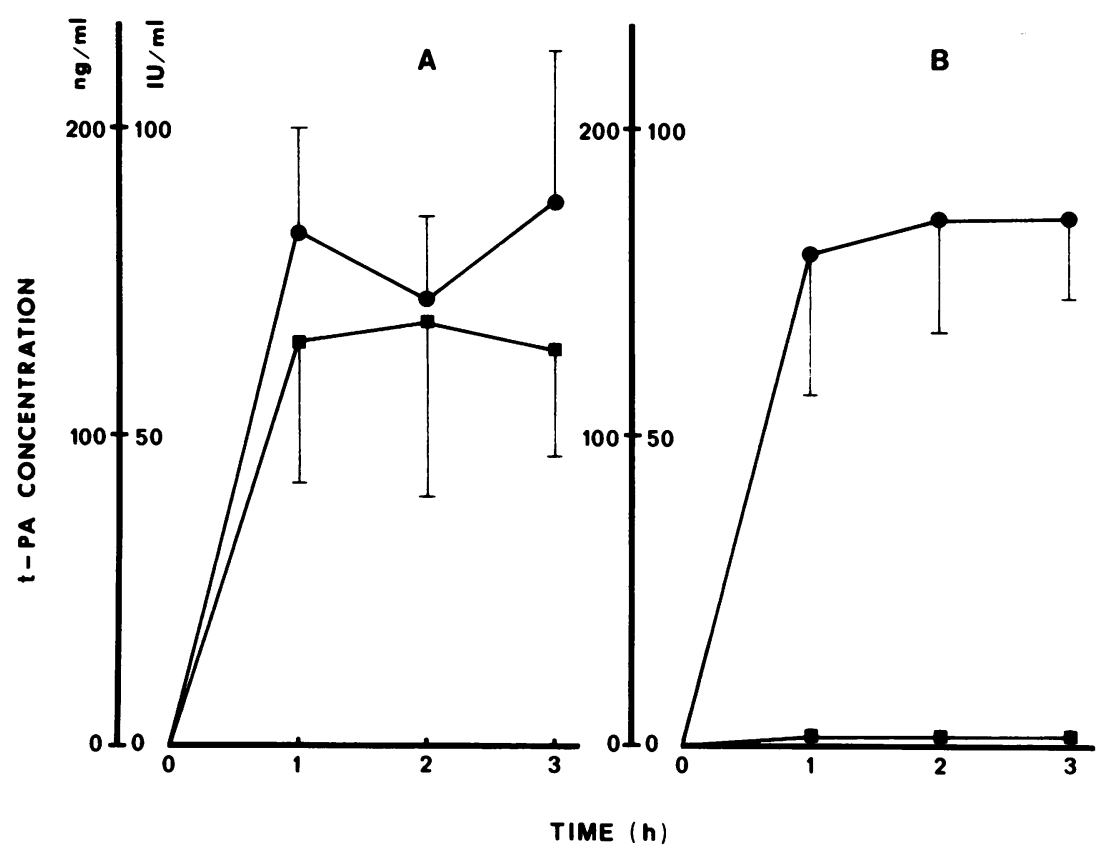

Figure 2. Plasma levels of t-PA antigen (๑) and activity ( $\square$ ) during infusion of t-PA. t-PA $(150,000$ $\mathrm{IU} / \mathrm{kg}$ body $\mathrm{wt}$ ) was infused over $4 \mathrm{~h}$ in control (A) and endotoxin-treated (B) rabbits. Results are the mean \pm SD of three experiments. Time 0 represents the preinfusion value. undetectable $(<1 \mathrm{IU} / \mathrm{ml})$ in endotoxin-treated rabbits. In this latter group, the absence of free t-PA was also assessed by gel filtration of samples collected on D-Ile-Pro-Arg- $\mathrm{CH}_{2} \mathrm{Cl}$ (not shown).

\section{In vitro experiments}

Inhibition of fibrin-associated t-PA by PA-inhibitor. Radiolabeled blood clots containing t-PA $(40 \mathrm{IU} / \mathrm{ml})$ were immersed in control or PA-inhibitor-rich rabbit plasma and the rate of lysis was calculated from the released radioactivity. As shown in Fig. $7 A$, PA-inhibitor-rich plasma inhibits clot lysis markedly although incompletely. For example, whole blood clots with incorporated t-PA underwent $30 \%$ lysis in PA-inhibitor-rich plasma in $4 \mathrm{~h}$ as compared with $62 \%$ in control plasma.

Addition of lung tissue slices $(\simeq 200 \mathrm{mg}$ ) to this system did not influence the rate of lysis of clots immersed in control plasma but significantly enhanced the rate of lysis of clots added to PA-inhibitor-rich plasma. The rate of lysis of t-PA-free clots immersed in control or PA-inhibitor-rich plasma was negligible, both in the presence and in the absence of lung tissue (Fig. 7 B).
Lysis of superfused blood clots. Results of thrombolysis of clots, superfused with rabbit plasma $(1.2 \mathrm{ml} / \mathrm{min})$ and t-PA (210 $\mathrm{IU} / \mathrm{min}$ ), which were mixed $5 \mathrm{~s}$ or $70 \mathrm{~s}$ prior to contact with the clot are summarized in Fig. 8. In the absence of t-PA, the extent of thrombolysis was negligible. When $175 \mathrm{IU} / \mathrm{ml}$ of t-PA was added to control rabbit plasma, $22 \pm 4 \%$ lysis was obtained, compared to $2 \pm 2 \%$ with PA-inhibitor-rich plasma. Similar results were obtained when heparinized plasma or whole blood was used instead of citrated plasma.

The addition of lung tissue slices, to the tube containing the labeled clot, had no influence on t-PA-induced thrombolysis in the presence of normal plasma, but markedly reduced the inhibitory effect of PA-inhibitor-rich plasma, resulting in $12 \pm 2 \%$ lysis (Fig. $8 \mathrm{~B}$ ). However, when t-PA was mixed for $70 \mathrm{~s}$ with PA-inhibitor-rich plasma prior to contact with the clot, thrombolysis was again undetectable. The presence of lung tissue did not result in a significant change $(<10 \%)$ of the t-PA activity in superfused control plasma nor of the PA-inhibitor activity in PA-inhibitor-rich plasma. Mixtures of PA-inhibitor-rich plasma and $t-P A$ thus yielded significant thrombolysis notwithstanding the fact that only minimal t-PA activity $(<2 \mathrm{IU} / \mathrm{ml})$ could be

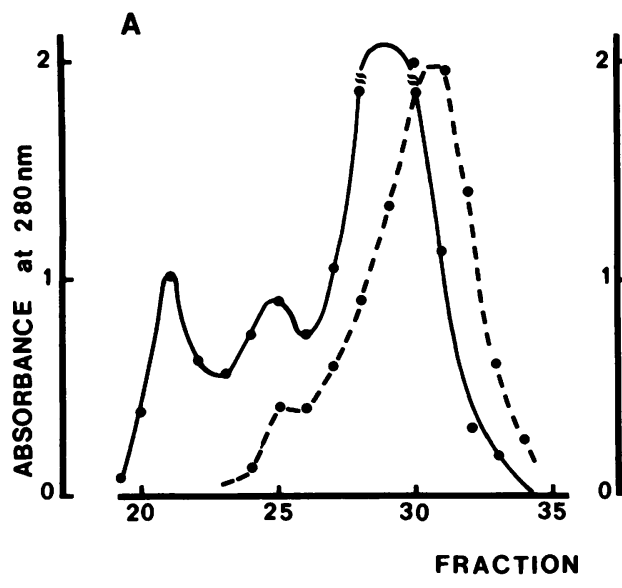

B

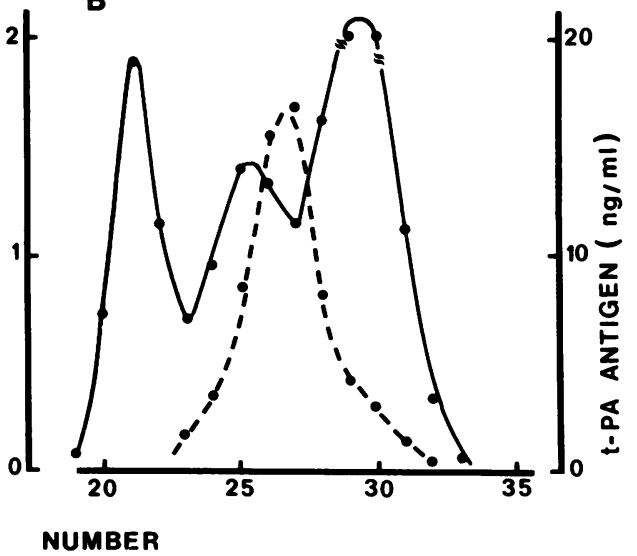

Figure 3. Gel filtration of plasma on Ultrogel AcA 44. Elution pattern of plasma samples from control $(A)$ or endotoxin-treated $(B)$ rabbits during infusion of t-PA $(150,000 \mathrm{IU} / \mathrm{kg}$ body wt over $4 \mathrm{~h}$ ). Plasma was obtained from blood samples collected on trisodium citrate and D-Ile-Pro-Arg- $\mathrm{CH}_{2} \mathrm{Cl}\left(2 \times 10^{-4}\right.$ $\mathrm{M}$ final concentration). Similar results were obtained with plasma samples collected after 2 and $3 \mathrm{~h}$ in each of three rabbits. $-\bullet$, absorbance at $280 \mathrm{~nm}$; $---\bullet---$, t-PA antigen $(\mathrm{ng} / \mathrm{ml})$. 


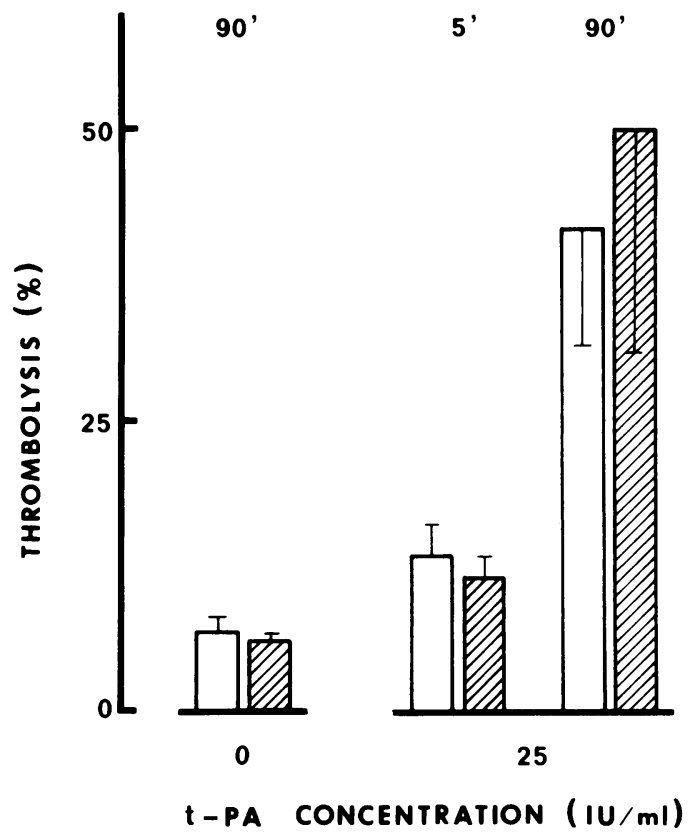

Figure 4. Thrombolysis by t-PA incorporated into the clot. t-PA ( 0 or $25 \mathrm{IU} / \mathrm{ml}$ ) was incorporated into the jugular vein thrombus in control (open bars) and endotoxin-treated (hatched bars) rabbits. The extent of thrombolysis was measured $5 \mathrm{~min}$ or $90 \mathrm{~min}$ after removal of the vein clamps. Results are the mean \pm SD of three experiments.

measured in the superfused plasma. Such t-PA activity was not significantly different from that measured in the superfused plasma in the absence of lung tissue or in plasma that had reacted $70 \mathrm{~s}$ with t-PA.

\section{Discussion}

PA-inhibitor, a specific inhibitor of t-PA and UK recently identified in plasma, may play a role in the regulation and control of physiologic fibrinolysis. Its low concentration in plasma has, so far, hampered its purification, and present information concerning its biological functions is mainly derived from plasma

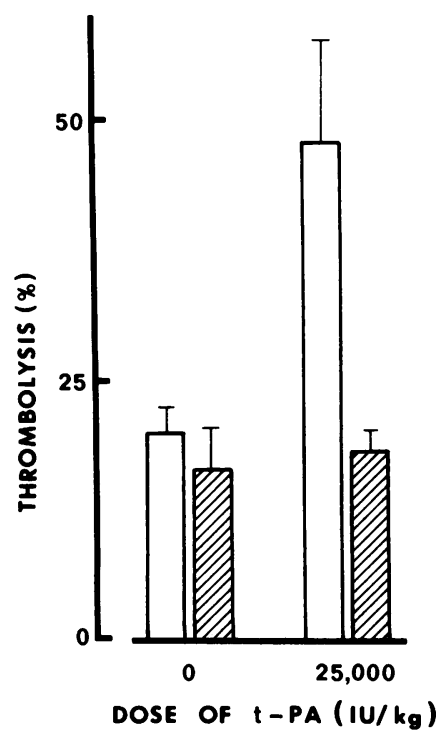

Figure 5. Lysis of jugular vein thrombi after infusion of $\mathrm{t}-\mathrm{PA}$ into a femoro-jugular arteriovenous shunt. t-PA $(25,000 \mathrm{IU} / \mathrm{kg}$ body wt) was infused over $4 \mathrm{~h}$ into the proximal part of the shunt. The extent of thrombolysis was measured at the end of the infusion in control (open bars) and endotoxin-treated (hatched bars) rabbits. Results are the mean $\pm S D$ of three experiments.

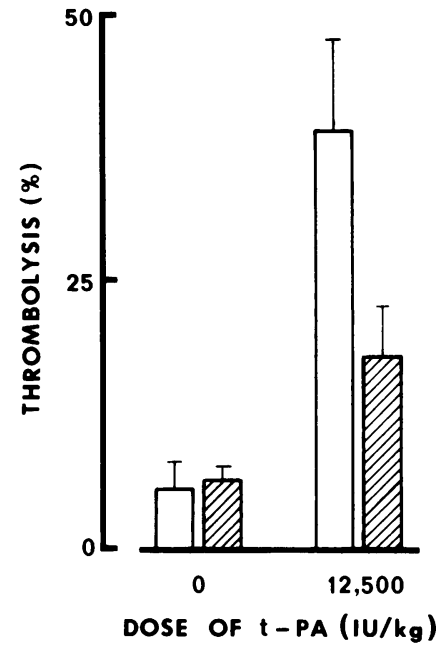

Figure 6. Lysis of blood clots placed in an extracorporeal femoro-femoral arteriovenous shunt. t-PA $(12,500 \mathrm{IU} / \mathrm{kg}$ body $w t$ ) was infused over $2 \mathrm{~h}$ into the proximal part of the shunt in control (open bars) and in endotoxin-treated (hatched bars) rabbits. Results are the mean \pm SD of three to four experiments.

samples with high levels of PA-inhibitor activity. Very low doses of endotoxin in rabbits induce a marked increase in the level of PA-inhibitor (10), which allow studies on the effect of PA-inhibitor on thrombolysis induced by t-PA infusion.

Systemic or local infusion of t-PA produced comparable degrees of thrombolysis in control (PA-inhibitor-poor) and endotoxin-treated (PA-inhibitor-rich) rabbits, even though the PAinhibitor was not saturated and no free t-PA activity could be demonstrated in plasma from endotoxin-treated rabbits.

Our observation that human t-PA, injected into rabbits, circulates mainly in its free form in the control animals and nearly exclusively as t-PA-PA-inhibitor complex in endotoxin-treated rabbits, raises the question whether t-PA-PA-inhibitor complex has intrinsic thrombolytic capacity in vivo. The results of Fig. 5 show that the contact of t-PA with PA-inhibitor-rich blood for $\sim 3$ min results in complete inhibition of its thrombolytic activity, suggesting that the (stabilized?) complex is inactive. During systemic infusion, the elapsed time interval between entrance of t-PA into the rabbit's circulation and the contact of the enzyme with the thrombus is $\sim 10 \mathrm{~s}$. It is possible that t-PA-PA-inhibitor complex may still be reversible when reaching the fibrin clot, and that fibrin might dissociate the complex yielding active t-PA. Attempts to measure t-PA accumulation on the clot surface during t-PA infusion both in control and endotoxin-treated animals were, however, unsuccessful.

t-PA incorporated into clots in vivo induces thrombolysis at the same rate in control and endotoxin-treated animals. In vitro, however, t-PA-containing blood clots immersed into PA-inhibitor-rich rabbit plasma lysed more slowly than clots immersed in control plasma, indicating that protection, by fibrin, of t-PA inhibition is less effective in vitro than in vivo.

To simulate the in vivo process of thrombolysis in vitro, a radiolabeled blood clot was superfused with mixtures of t-PA and PA-inhibitor-rich plasma. With an incubation time of t-PA and PA-inhibitor of $5 \mathrm{~s}$ before contact with the clot, with a concentration of PA-inhibitor of $320 \mathrm{ng} / \mathrm{ml}(\simeq 7 \mathrm{nM})$ and of $\mathrm{t}-\mathrm{PA}$ of $340 \mathrm{ng} / \mathrm{ml}$ ( $\simeq 5 \mathrm{nM}$ ), and assuming a rate constant of the interaction between the two proteins of $3.10^{7} \mathrm{M}^{-1} \mathrm{~s}^{-1}$, we anticipate that $40 \%$ of the activator reaches the clot as free enzyme. Notwithstanding this, no lysis occurred within $1 \mathrm{~h}$, whereas $22 \%$ lysis was obtained when t-PA was mixed with control plasma. This indicates that even if t-PA accumulates on the clot surface, PA-inhibitor efficiently neutralizes its activity in vivo. Replace- 


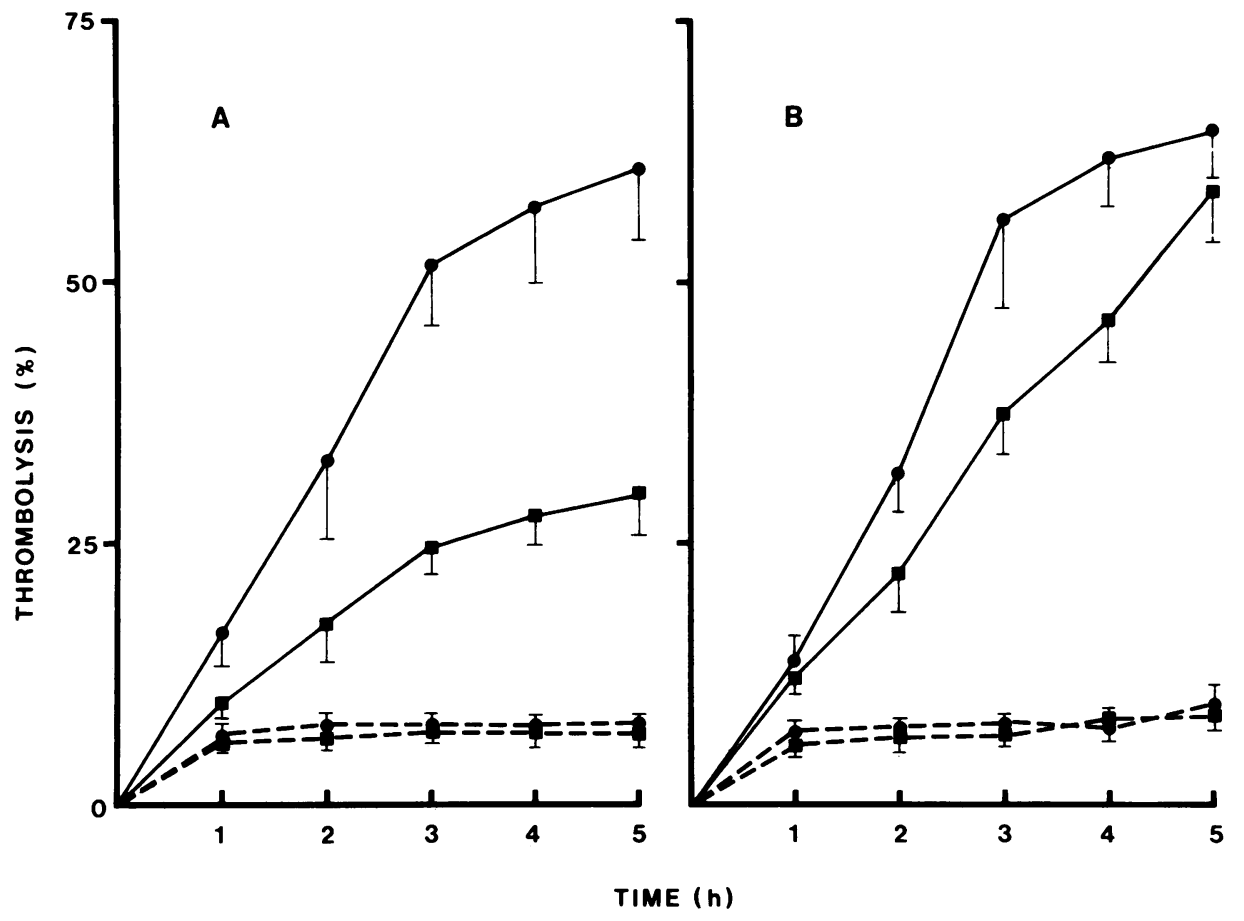

Figure 7. In vitro thrombolysis induced by $\mathrm{t}-\mathrm{PA}(40 \mathrm{IU} / \mathrm{ml})$ incorporated into blood clots immersed in control (•) or PA-inhibitor-rich plasma ( $($ ). Experiments were performed in the absence $(A)$ and in the presence $(B)$ of lung slices. t-PA concentration in the clot was: (- - -), $0 \mathrm{IU} / \mathrm{ml}$; (-), $40 \mathrm{IU} / \mathrm{ml}$. Each value is the mean \pm SD of four experiments. ment of citrated plasma by heparinized PA-inhibitor-rich plasma or whole blood also did not result in clot lysis, suggesting that calcium ions and blood cells do not interfere with the interaction between t-PA and PA-inhibitor on the fibrin surface. However, when a rabbit lung slice was added to the system in the vicinity of the clot, significant lysis occurred following superfusion with mixtures of t-PA and PA-inhibitor-rich plasma. Plasma samples

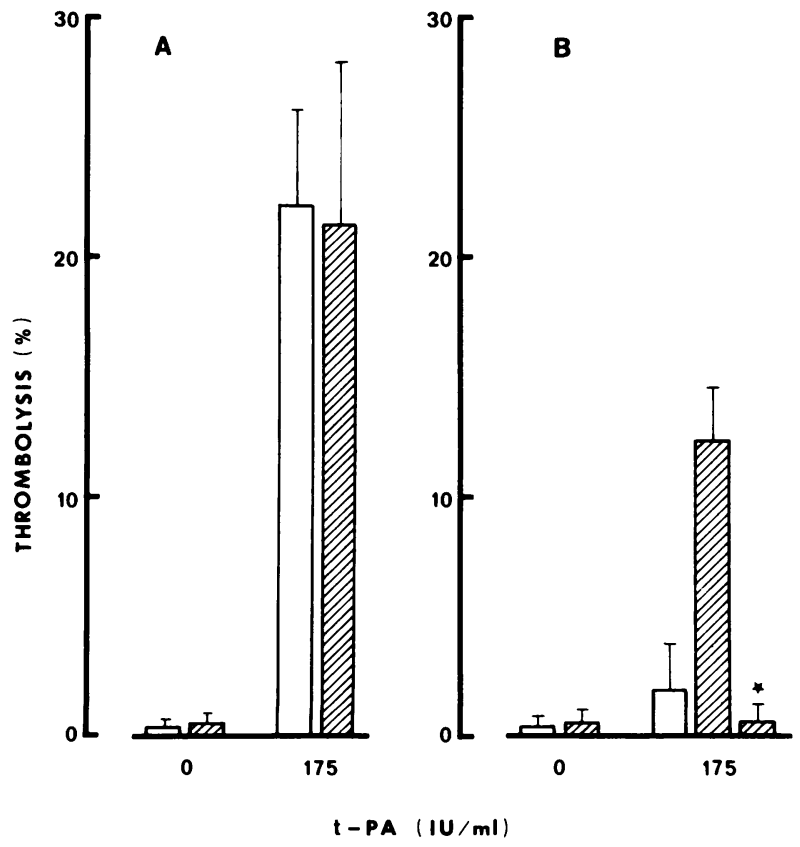

Figure 8. In vitro lysis of whole blood clots superfused with mixtures of t-PA or solvent and control rabbit plasma $(A)$ or PA-inhibitor-rich plasma $(B)$. t-PA and plasma were mixed for 5 or $70 \mathrm{~s}(\star)$ prior to contact with the clot. Experiments were carried out in the absence (open bars) and in the presence (hatched bars) of lung tissue slices. Results are the mean $\pm \mathrm{SD}$ of three to five experiments. taken from the incubation mixture had only minimal t-PA activity $(<2 \mathrm{IU} / \mathrm{ml})$. The lung tissue did not induce clot lysis in the absence of t-PA nor enhanced the thrombolytic activity of mixtures of t-PA and PA-inhibitor-poor plasma. It seems, therefore, that in the presence of lung tissue the thrombolytic activity of t-PA is, at least partially, protected from inhibition by PA-inhibitor. Such protective effect by lung tissue was also visible when t-PA-containing blood clots were incubated in PAinhibitor-rich plasma. This is not due to uptake or neutralization of PA-inhibitor by the lung tissue because superfusion of the lung tissue slice with PA-inhibitor-rich plasma without t-PA was not associated with any change of the PA-inhibitor level.

Delayed inhibition of t-PA by PA-inhibitor in the presence of lung tissue seems to occur at the fibrin surface and not in solution, because no t-PA activity could be recovered in plasma and because lung tissue does not influence the rate of interaction between t-PA and PA-inhibitor in rabbit plasma in vitro. The lung tissue did not restore the thrombolytic activity of mixtures of t-PA and PA-inhibitor-rich plasma incubated for about $1 \mathrm{~min}$, indicating that it does not dissociate the (stabilized?) t-PA-PAinhibitor complex.

All these findings taken together suggest the existence of one or more tissue-derived components that play a role in the regulation of thrombolysis in vivo. Fig. 6 shows that a clot placed in an extracorporeal loop in endotoxin-treated rabbits undergoes significant lysis when t-PA is infused in the proximal segment, suggesting that the interference with the inhibition of t-PA by PA-inhibitor is caused by a secreted component. However, we were unable to demonstrate any interference with t-PA-induced thrombolysis in saline extracts of lung tissue or in conditioned medium of short-term lung cultures. One major problem in studying this thrombolysis modulating component is that it appears to be very labile and that there are no simple methods to assay its activity.

In summary, our data show that the thrombolytic activity of t-PA infused in rabbits with an experimental jugular vein thrombosis is not affected by the presence of high concentra- 
tions of circulating PA-inhibitor, which rapidly inhibits t-PA. Evidence is provided that one or more tissue-derived factors, possibly of endothelial cell origin, may modulate the interaction between t-PA and PA-inhibitor at the level of fibrin, but the nature, origin, and exact mechanism of action of this hypothetical novel fibrinolytic component(s) remain(s) to be elucidated.

\section{Acknowledgments}

This study was supported by grants from the Geconcerteerde Onderzoeksactie and from the Fonds voor Geneeskundig Wetenschappelijk Onderzoek.

\section{References}

1. Collen, D. 1980. On the regulation and control of fibrinolysis. Thromb. Haemostasis. 43:77-89.

2. Kruithof, E. K. O., C. Tran-Thang, A. Ransijn, and F. Bachmann. 1984. Demonstration of a fast acting inhibitor of plasminogen activators in human plasma. Blood. 64:907-913.

3. Chmielewska, J., M. Rånby, and B. Wiman. 1983. Evidence for a rapid inhibitor to tissue plasminogen activator in plasma. Thromb. Res. 31:427-436.

4. Juhan-Vague, I., B. Moerman, F. De Cock, M. F. Aillaud, and D. Collen. 1984. Plasma levels of a specific inhibitor of tissue-type plasminogen activator (and urokinase) in normal and pathological conditions. Thromb. Res. 33:523-530.

5. Thorsen, S., and M. Philips. 1984. Isolation of tissue-type plasminogen activator-inhibitor complex from human plasma. Evidence for a rapid plasminogen activator inhibitor. Biochim. Biophys. Acta. 802: 111-118.

6. Verheijen, J. H., G. T. G. Chang, and C. Kluft. 1984. Evidence for the occurrence of a fast-acting inhibitor for tissue-type plasminogen activator in human plasma. Thromb. Haemostasis. 51:392-395.

7. Emeis, J. J., W. M. Van Hinsbergh, J. H. Verheijen, and G. Wijngaards. 1983. Inhibition of tissue-type plasminogen activator by conditioned medium from cultured human and porcine vascular endothelial cells. Biochem. Biophys. Res. Commun. 110:392-398.

8. Loskutoff, D. J., J. A. van Mourik, L. A. Erickson, and D. Lawrence. 1983. Detection of an unusually stable fibrinolytic inhibitor produced by bovine endothelial cells. Proc. Natl. Acad. Sci. USA. 80:2956-2960.

9. Levin, E. G. 1983. Latent tissue plasminogen activator produced by human endothelial cells in culture: evidence for an enzyme-inhibitor complex. Proc. Natl. Acad. Sci. USA. 80:6804-6808.

10. Colucci, M., J. A. Paramo, and D. Collen. 1985. Generation in plasma of a fast-acting inhibitor of plasminogen activator in response to endotoxin stimulation. J. Clin. Invest. 75:818-824.

11. Kluft, C., J. H. Verheijen, P. Cooper, G. T. G. Chang, A. F. H.
Jie, S. L. Blamey, G. D. O. Lowe, C. D. Forbes, and F. E. Preston. 1984. Postoperative changes in the activity in blood of extrinsic (tissue-type) plasminogen activator and its fast-acting inhibitor. Haemostasis. 14:26.

12. Wiman, B., G. Csemiczky, L. Marsk, and H. Robbe. 1984. The fast inhibitor of tissue plasminogen activator in plasma during pregnancy. Thromb. Haemostasis. 52:124-126.

13. Nilsson, I. M., and L. Tengborg. 1984. A family with thrombosis associated with high level of tissue plasminogen activator inhibitor. Haemostasis. 14:24.

14. Zamarron, C., H. R. Lijnen, and D. Collen. 1984. Influence of exogenous and endogenous tissue-type plasminogen activator on the lysability of clots in a plasma milieu in vitro. Thromb. Res. 35:335-345.

15. Rijken, D. C., and D. Collen. 1981. Purification and characterization of the plasminogen activator secreted by human melanoma cells in culture. J. Biol. Chem. 256:7035-7041.

16. Deutsch, D. G., and E. T. Mertz. 1970. Plasminogen: purification from human plasma by affinity chromatography. Science (Wash. DC). 170:1095-1096.

17. Blombäck, B., and M. Blombäck. 1956. Purification of human and bovine fibrinogen. Ark. Kemi. 10:415-428.

18. Verheijen, J. H., E. Mullaart, G. T. G. Chang, C. Kluft, and G. Wijngaards. 1982. A simple sensitive spectrophotometric assay for extrinsic (tissue-type) plasminogen activator applicable to measurements in plasma. Thromb. Haemostasis. 48:266-269.

19. Fraker, P. J., and J. C. Speck Jr. 1978. Protein and cell membrane iodinations with a sparingly soluble chloroamide, 1,3,4,6-tetra-chloro3a,6a-diphenylglycoluril. Biochem. Biophys. Res. Commun. 80:849-857.

20. Lijnen, H. R., M. Uytterhoeven, and D. Collen. 1984. Inhibition of trypsin-like proteinases by tripeptide arginyl and lysyl chloromethylketones. Thromb. Res. 34:431-437.

21. Gaffney, P. J., and A. D. Curtis. 1985. A collaborative study of a proposed international standard for tissue plasminogen activator (t-PA). Thromb. Haemostasis. 53:134-136.

22. Collen, D., J. M. Stassen, and M. Verstraete. 1982. Thrombolysis with human extrinsic (tissue-type) plasminogen activator in rabbits with experimental jugular vein thrombosis. J. Clin. Invest. 71:368-376.

23. Korninger, C., and D. Collen. 1981. Studies on the specific fibrinolytic effect of human extrinsic (tissue-type) plasminogen activator in human blood and in various species in vitro. Thromb. Haemostasis. 46:561-566.

24. Astrup, T., and S. Müllertz. 1952. Fibrin plate method for estimating fibrinolytic activity. Arch. Biochem. Biophys. 40:346-351.

25. Rijken, D. C., I. Juhan-Vague, F. De Cock, and D. Collen. 1983. Measurement of human tissue-type plasminogen activator by a two-site immunoradiometric assay. J. Lab. Clin. Med. 101:274-284.

26. Vermylen, C., R. De Vreker, and M. Verstraete. 1963. A rapid enzymatic method for assay of fibrinogen fibrin polymerization time (FPT-test). Clin. Chim. Acta. 8:418-424.

27. Edy, J., F. De Cock, and D. Collen. 1976. Inhibition of plasmin by normal and antiplasmin-depleted plasma. Thromb. Res. 8:513-515. 